Applied Surface Science 257 (2011) 10815-10820

http://dx.doi.org/10.1016/j.apsusc.2011.07.109

\title{
Structure-property and composition-property relationships for poly(ethylene terephthalate) surfaces modified by helium plasma-based ion implantation
}

\author{
A. Tóth ${ }^{1, *}$, M. Veres ${ }^{2}$, K. Kereszturi ${ }^{1}$, M. Mohai ${ }^{1}$, I. Bertóti $^{1}$, J. Szépvölgyi ${ }^{1}$ \\ ${ }^{1}$ Institute of Materials and Environmental Chemistry, Chemical Research Center, \\ Hungarian Academy of Sciences, H-1525 Budapest, P.O. Box 17, Hungary
}

${ }^{2}$ Research Institute for Solid State Physics and Optics of the Hungarian Academy of Sciences, H-1525 Budapest, P.O. Box 49, Hungary

\begin{abstract}
The surfaces of untreated and helium plasma-based ion implantation (He PBII) treated poly(ethylene terephthalate) (PET) samples were characterised by reflectance colorimetry, contact angle studies and measurements of surface electrical resistance. The results were related to the structural and compositional data obtained by the authors earlier on parallel samples by XPS and Raman spectroscopy. Inverse correlations between lightness and $I_{D} / I_{G}$ ratio and between chroma and $I_{D} / I_{G}$ ratio were obtained, suggesting that the PBII-treated PET samples darken and their colourfulness decreases with the increase of the portion of aromatic $\mathrm{sp}^{2}$ carbon rings in the chemical structure of the modified layer. Direct correlation between water contact angle and the $I_{D} / I_{G}$ ratio and inverse correlations between surface energy and $I_{D} / I_{G}$ ratio and between dispersive component of surface energy and $I_{D} / I_{G}$ ratio were found, reflecting that surface wettability, surface energy and its dispersive component decrease with the formation of surface structure, characterised again by enhanced portion of aromatic $\mathrm{sp}^{2}$ carbon rings. The surface electrical resistance decreased with the increase of the surface Ccontent determined by XPS and also with the increase of the surface concentration of conjugated double bonds, reflected by the increase of the $\pi \rightarrow \pi^{*}$ shake-up satellite of the $\mathrm{C} 1 \mathrm{~s}$ peak.
\end{abstract}

Keywords: poly(ethylene terephthalate), plasma-based ion implantation, colorimetry, wettability, electrical resistance

\section{Introduction}

Plasma-based ion implantation (PBII), called also plasma immersion ion implantation (PIII or $\mathrm{PI}^{3}$ ) is a versatile, relatively simple and cost-effective surface modification technique, alternative to conventional ion implantation. PBII treatment of poly(ethylene terephthalate) (PET) is a subject of current interest, due to promising applications in areas including packaging and biomaterial devices [1,2 and references therein]. Recently we studied the surface modification of PET by He PBII, applying XPS and Raman spectroscopy, including the effect of the main process parameters (acceleration voltage, fluence and fluence rate) on the alterations of the surface chemical composition and structure [2]. An important feature of using helium for PBII treatment is that in the energy range of interest of PBII treatment (actually above $2 \mathrm{keV}$ ), the stopping power of PET for $\mathrm{He}^{+}$ions is dominated by the electronic component [2], and therefore the structure of the modified layer may become ordered [3]. Due to its small atomic size, $\mathrm{He}^{+}$ion has a relatively large projected range, as

\footnotetext{
* Corresponding author.

E-mail address: totha@chemres.hu (A. Tóth)
} 
compared to those of heavier ions of the same energy, and therefore the application of $\mathrm{He}$ plasma gas during the PBII treatment can be advantageous from the point of view of achieving relatively large modification depths.

In this paper, we study the changes in colour, wettability and surface electrical resistance for PET modified by He PBII treatments and report related structure-property and composition-property relationships. The significance of this study is that such relationships can be important in manufacturing and application of materials in general, and of PBII-treated materials in particular [1,4-10].

\section{Experimental details}

\subsection{Material applied, sample preparation and treatment}

The specimens studied in this work consisted of a sample set parallel to that prepared by He PBII treatment and studied by XPS and Raman spectroscopy in our previous work [2]. For clarity, we briefly describe also here the conditions of sample preparation and PBII treatment.

Poly(ethylene terephthalate) (PET) of the type Docapet (Ensinger), virgin grade was used, from which discs of $10 \mathrm{~mm}$ diameter and $2 \mathrm{~mm}$ thickness were machined. These were polished with SiC paper (grit number P1200 and P4000) and then with felt sheet.

PET samples were treated by helium plasma-based ion implantation, applying a $27.13 \mathrm{MHz}$ RF plasma generator (Dressler, Germany) and a high voltage pulser (ANSTO, Australia). The base pressure was about $5 \times 10^{-5} \mathrm{~Pa}$. High purity (4N5) He gas was used with a flow rate $=25$ $\mathrm{cm}^{3} \cdot \mathrm{min}^{-1}(\mathrm{STP})$ and pressure $=4.8 \times 10^{-1} \mathrm{~Pa}$. RF power $=150 \mathrm{~W}$ and pulse duration $=5 \mu \mathrm{s}$ were applied. The plasma density was $n=1.5 \times 10^{16} \mathrm{~m}^{-3}$. The pulse frequency was varied between 65 and $218 \mathrm{~Hz}$, to adjust the desired fluence rate. To diminish the number of samples to be prepared and investigated, the approach of design of experiments was applied. A threelevel fractional factorial design was used with three factors (acceleration voltage $(U)$, fluence $(F)$, and fluence rate $(F R)$ ) and nine treatment combinations, in randomised order. $U$ between 15 and $30 \mathrm{kV}, F$ between $1 \times 10^{17}$ and $3 \times 10^{17} \mathrm{~cm}^{-2}$ and $F R$ between $3 \times 10^{13}$ and $7 \times 10^{13} \mathrm{~cm}^{-2} \mathrm{~s}^{-1}$ have been applied.

\subsection{Colorimetric studies}

The colour of the samples was characterised by the coordinates of the Commission Internationale de l'Eclairage (International Commission on Illumination) CIELAB 1976 space of colours: lightness $L^{*}$ and chromaticity dimensions $a^{*}$ and $b^{*}$. In this system of rectangular coordinates $a^{*}$ measures redness when positive and greenness when negative, while $b^{*}$ measures yellowness when positive and blueness when negative. The zero value corresponds to grey. A Spectro-Guide 45/0 Gloss type commercial colour spectrophotometer (BYKGardner GmbH, Germany) was applied for the determination of $L^{*}, a^{*}$ and $b^{*}$. The estimated error was $\pm 10 \%$. The values of the basic characteristics chroma $C_{a b}$ and hue $h_{a b}$ were calculated according to equations 1 and 2, respectively [11]:

$$
\begin{aligned}
& C_{a b}=\sqrt{a^{2}+b^{2}} \\
& h_{a b}=\operatorname{Arctan} \frac{b^{*}}{a^{*}}
\end{aligned}
$$

Chroma is the colourfulness relative to the brightness of another colour, which appears white under similar viewing conditions. Hue is the characteristic associated with a colour name and is a gradation of colour advanced by degrees. Lightness is the characteristic that allows the colour to be ranked on a scale from dark to light and is expressed as a parameter ranging from 0 to $100 \%$ (with black being 0 and white being $100 \%$ ). 


\subsection{Wettability measurements}

Contact angles were measured by the static sessile drop method at $23{ }^{\circ} \mathrm{C}$, with double distilled water and diiodomethane (Sigma-Aldrich, Reagent Plus 99\% grade), applying the SEE System apparatus (Advex Instruments, Czech Republic). A Hamilton syringe was used to inject $2 \mu \mathrm{l}$ droplets. Each result of contact angle is an average of five measurements, performed always on previously non-wetted parts of the samples. The surface free energy and its polar and dispersive components were calculated by the method of Owens and Wendt [12].

\subsection{Surface electrical resistance}

Surface electrical resistance was determined at room temperature, within 1 hour after treatment, considering the ASTM D257 standard test method for DC resistance, by a homeassembled equipment, based on a P-263 type power supply (Physik Instrumente, Germany) and a home-made digital picoamper-meter. The estimated error was $\pm 10 \%$.

\section{Results and discussion}

\subsection{Changes in chemical composition and structure}

The compositional and structural analyses of the He PBII-treated PET samples by XPS and Raman spectroscopy were described in our previous paper [2], in which relationships of the treatment parameters with XPS and Raman results were also discussed. It was found that the C-content of the modified layer increased with the increase of fluence rate and acceleration voltage and the area ratio of the $\mathrm{D}$ to $\mathrm{G}$ band increased with the increase of fluence and the increase of acceleration voltage.

Table 1

Treatment parameters, surface C-content and area ratio of the D and G Raman bands

\begin{tabular}{cccccc}
\hline Sample & $\begin{array}{c}\text { Voltage } \\
\boldsymbol{U}\end{array}$ & $\begin{array}{c}\text { Fluence } \\
\mathbf{F V} \times \mathbf{1 0}^{\mathbf{1 7}} \\
\mathbf{c m}^{-\mathbf{2}}\end{array}$ & $\begin{array}{c}\text { Fluence rate } \\
\boldsymbol{F R} \times \mathbf{1 0} \\
\mathbf{c m}^{\mathbf{- 2}} \mathbf{s}^{\mathbf{- 1}}\end{array}$ & $\begin{array}{c}\text { C-content } \\
\boldsymbol{C} \\
\mathbf{a t} \mathbf{\%}\end{array}$ & $\begin{array}{c}\text { Area ratio } \\
\boldsymbol{I}_{\boldsymbol{D}} \boldsymbol{I}_{\boldsymbol{G}}\end{array}$ \\
\hline Untreated & na & na & na & 72.4 & na \\
\hline N1 & 15 & 2 & 3 & 83.5 & 1.08 \\
\hline N2 & 30 & 2 & 5 & 87.6 & 1.38 \\
\hline N3 & 22.5 & 2 & 7 & 88.1 & 1.15 \\
\hline N4 & 15 & 1 & 5 & 80.3 & 0.76 \\
\hline N5 & 15 & 3 & 7 & 86.5 & 1.01 \\
\hline N6 & 30 & 1 & 7 & 87.6 & 0.96 \\
\hline N7 & 22.5 & 1 & 3 & 84.9 & 1.25 \\
\hline N8 & 22.5 & 3 & 5 & 86.8 & 1.31 \\
\hline N9 & 30 & 3 & 3 & 83.1 & 1.18 \\
\hline
\end{tabular}

For correlation purposes later in this work, we cite in Table 1 the XPS results on the surface C-content. Note that these reflect increased values after He PBII treatment. 


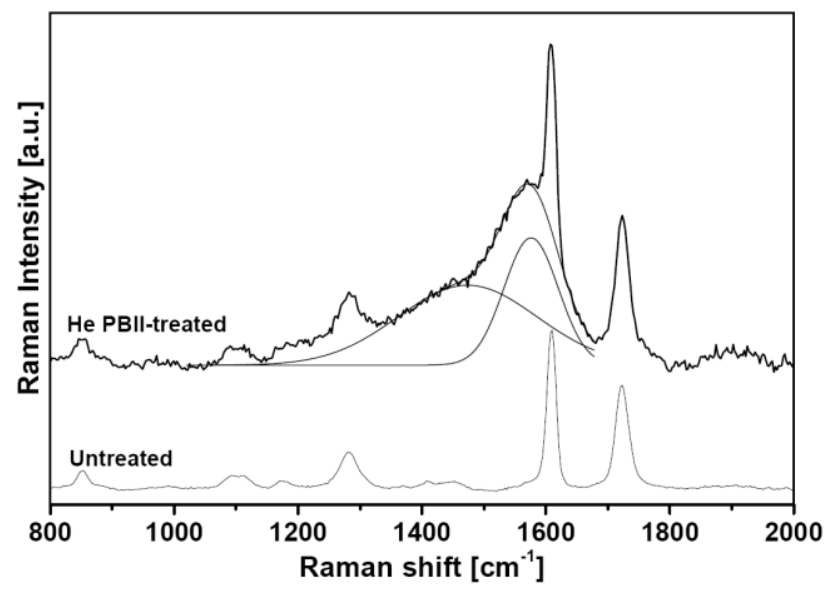

Fig. 1 Raman spectra measured for the untreated PET sample and for the He PBII-treated sample N1, with the indication of the D and G bands

Fig. 1 exemplifies the development of a broad asymmetric Raman peak upon He PBIItreatment, due to the formation of amorphous carbon layer at the surface, and the decomposition of this peak into D (disordered) and $\mathrm{G}$ (graphitic) components. The area ratios of these components $\left(I_{D} / I_{G}\right)$ obtained previously [2] by such a decomposition for the modified samples are also cited in Table 1, for purposes of subsequent correlation with colorimetric and wettability properties.

Raman spectroscopy is known to be a sensitive tool for the characterisation of carbonbased materials, but it is not a straightforward matter to find relationships between spectral features and chemical structures. We remind that in case of amorphous carbons, the Raman spectra are interpreted based on the following findings [13-15]:

Amorphous carbon structure consists of $\mathrm{sp}^{2}$ and $\mathrm{sp}^{3}$ hybridised carbon atoms (and often hydrogen), but the distribution of these atoms in the structure is not uniform. The $\mathrm{sp}^{2}$ hybridised C atoms bond to each other preferentially, forming $\mathrm{sp}^{2}$ "islands" (or clusters) in the $\mathrm{sp}^{3}$ "ocean" (or matrix). The properties of the $\mathrm{sp}^{2}$ clusters are determined by the topology of the $\mathrm{sp}^{2}$ atoms, which is complex. However, rings and chains can be determined as the main units. These rings and chains are interconnected and crosslinked with each other.

The Raman scattering cross-section of the $\mathrm{sp}^{2}$ clusters is several orders of magnitude higher than that of the $\mathrm{sp}^{3}$ matrix (when using visible excitation), therefore the Raman spectrum is dominated by the bands of $\mathrm{sp}^{2}$ clusters.

The Raman spectrum of amorphous carbons consists of the so-called D and G bands. It is accepted that the D band (located around 1300-1400 $\mathrm{cm}^{-1}$ ) arises from the breathing vibrations of rings formed by $\mathrm{sp}^{2} \mathrm{C}$ atoms (similarly to Raman scattering in graphite), while the $\mathrm{G}$ band (around 1500-1600 $\mathrm{cm}^{-1}$ ) is related to the stretching vibrations of $\mathrm{sp}^{2}$ carbon atoms, forming either rings or chains. It is remarkable that conjugated chains and crosslinks contribute to the $\mathrm{G}$ peak only, while $\mathrm{sp}^{2}$ rings contribute to both of the two peaks.

From the above findings it follows that a relative increase in the intensity of the D band as compared to that of the $\mathrm{G}$ band $\left(I_{D} / I_{G}\right)$ indicates an increasing amount of $\mathrm{sp}^{2}$ carbon rings in the chemical structure of the amorphous carbon. Therefore, the $I_{D} / I_{G}$ ratio will be utilised in this work as a quantitative parameter for structural comparison. 


\subsection{Changes in colorimetric properties}

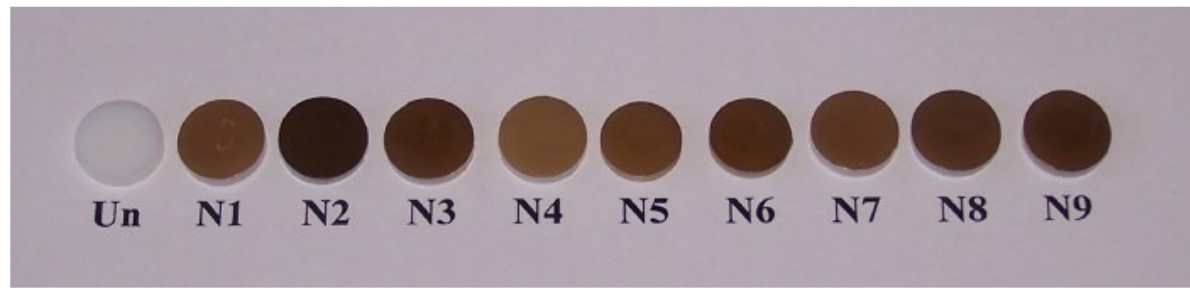

Fig. 2 Photographic image of the untreated and He PBII-treated PET samples

Fig. 2 demonstrates the photographic image of the untreated and He PBII-treated PET samples. A remarkable darkening can be observed for each treated sample. Reflectance colorimetry was used to determine the changes in the colorimetric properties, since it is capable of measuring even small colour differences. The colorimetric characteristics for the untreated and He PBII-treated samples are collected in Table 2.

Table 2

\section{Colorimetric characteristics of the untreated and PBII-treated PET samples}

\begin{tabular}{cccccc}
\hline Sample Lightness & \multicolumn{2}{c}{ Chromaticity } & & \\
& $\boldsymbol{L}^{*}$ & $\boldsymbol{a}^{*}$ & $\boldsymbol{b}^{*}$ & $\boldsymbol{C}_{\boldsymbol{a} \boldsymbol{b}}$ & $\boldsymbol{h}$ \\
& & & & & deg \\
\hline Untreated & 85.5 & -2.2 & -4.5 & 5.1 & 64.1 \\
\hline N1 & 50.6 & 7.2 & 10.0 & 12.3 & 54.1 \\
\hline N2 & 35.2 & 2.9 & 3.0 & 4.2 & 45.5 \\
\hline N3 & 43.9 & 2.8 & 10.9 & 11.3 & 75.6 \\
\hline N4 & 61.6 & 5.6 & 16.6 & 17.5 & 71.3 \\
\hline N5 & 53.3 & 7.4 & 12.1 & 14.2 & 58.8 \\
\hline N6 & 50.6 & 5.3 & 14.2 & 15.2 & 69.6 \\
\hline N7 & 25.9 & 2.9 & 9.3 & 9.8 & 73.0 \\
\hline N8 & 34.2 & 1.1 & 7.8 & 7.9 & 82.2 \\
\hline N9 & 49.8 & 5.0 & 5.5 & 7.5 & 47.9 \\
\hline & & & & & \\
\hline
\end{tabular}

It is clearly seen that - in agreement with our visual perception - the lightness decreased substantially upon treatment, from 85.5 to values ranging between 25.9 and 61.6. For the untreated sample small negative values of chromaticity dimensions $a^{*}$ and $b^{*}$ were detected, implying slight greenish and bluish tones for this sample. Upon PBII treatment, however, both $a^{*}$ and $b^{*}$ turned into positive, meaning the transformation of colour tones into reddish and yellowish. Chroma (related to colourfulness or saturation) essentially increased as a result of treatment, suggesting the increase of concentration of chromophore groups. Regarding the nature of the possible chromophores, even the untreated PET is reported to have a chromophore group in its main chain. However, it absorbs at $\lambda=310 \mathrm{~nm}$ [16], leading to molecular scission [17]. (UV radiation is known to be present in low temperature He plasma [18]). Discoloration of PET was already observed on UV-treatment - where the photodegradation was attributed to the ester carbonyl group as chromophore [19] - and on ion 
beam treatment [20]. It was emphasised that after the onset of irradiation, new chromophores might become important [19]. In another publication, the build up of conjugated aromatic structures was considered a part of the colour formation process [21]. The appearance of metallic lustre on ion beam-modified polymers - observed also in the present work - was explained by scattering of light on the abundant $\pi$-electrons [22]. The possible formation of aromatic structures (with extended $\pi$-electron configuration) is in agreement with the changes in the Raman spectra, discussed in point 3.1.

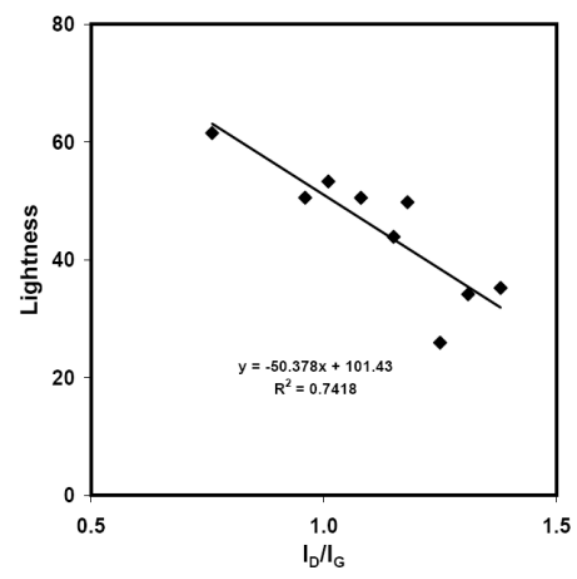

Fig. 3 Lightness versus area ratio of the D and G Raman bands

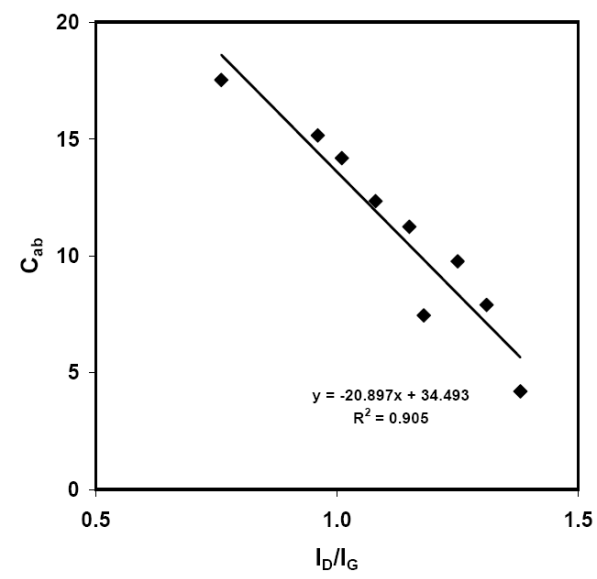

Fig. 4 Chroma versus area ratio of the $\mathrm{D}$ and G Raman bands

We looked for structure-property relationships by trying to interrelate the structural parameter determined by Raman spectroscopy and the colorimetric characteristics. Definite inverse correlations were found, apparently for the first time, between lightness and $I_{D} / I_{G}$ ratio (Fig. 3) and between chroma and $I_{D} / I_{G}$ ratio (Fig. 4). No correlation between hue and $I_{D} / I_{G}$ was detected. Considering the structural interpretation of the changes in the $I_{D} / I_{G}$ ratio described in point 3.1, the observed inverse correlations suggest that the PBII-treated PET samples darken and their colourfulness decreases (that is their colour approaches to grey) with the increase of the portion of $\mathrm{sp}^{2}$ carbon rings in the chemical structure of the modified layer.

\subsection{Changes in wettability}

Table 3 collects the contact angles $\Theta_{w}$ and $\Theta_{D I M}$, measured respectively with water and diiodomethane, for the untreated and PBII-treated samples. In addition, the calculated values of the total surface energy $\gamma_{\text {tot }}$ and its polar $\gamma_{\text {polar }}$ and dispersive $\gamma_{\text {disp }}$ components are also reported. Comparing the wettability and surface energy data characteristic for the untreated sample with the corresponding data obtained for the PBII-treated samples in Table 3, it can be seen that $i) \Theta_{w}$ decreases (from $61^{\circ}$ to values ranging between 41 and $58^{\circ}$ ), ii) $\gamma_{\text {disp }}$ increases significantly (from $10 \mathrm{~mJ} \mathrm{~m}^{-2}$ to values ranging between 13 and $22 \mathrm{~mJ} \mathrm{~m}^{-2}$ ) and iii) $\gamma_{t o t}$ also tends to increase (from 56 to values up to $68 \mathrm{~mJ} \mathrm{~m}^{-2}$ ). These changes may occur due to the plasma-based generation of long-lived radicals on the polymer surface. Comparing the obtained values of water contact angle and surface energy with those published for amorphous hydrogenated carbon (respectively $55 \leq \Theta_{w} \leq 70^{\circ}$ and $40 \leq \gamma_{t o t} \leq 44 \mathrm{~mJ} \mathrm{~m}^{-2}$ ) [23], values of $\Theta_{w}$ essentially lower and $\gamma_{t o t}$ higher were detected in this work for the PBII-treated samples, obviously due the residual O-content of the modified surface layers. 
Table 3

Contact angles, surface energy and its components for the untreated and PBII-treated PET samples

\begin{tabular}{cccccc}
\hline Sample & $\begin{array}{c}\boldsymbol{\theta}_{\boldsymbol{w}} \\
\mathbf{d e g}\end{array}$ & $\begin{array}{c}\boldsymbol{\theta}_{\text {DIM }} \\
\mathbf{d e g}\end{array}$ & $\begin{array}{c}\boldsymbol{\gamma}_{\text {tot }} \\
\mathbf{m J} \mathbf{~ m}^{-2}\end{array}$ & $\begin{array}{c}\boldsymbol{\gamma}_{\text {polar }} \\
\mathbf{m J} \mathbf{~ m}^{-2}\end{array}$ & $\begin{array}{c}\boldsymbol{\gamma}_{\text {disp }} \\
\mathbf{m J} \mathbf{~ m}^{-2}\end{array}$ \\
\hline Untreated & 61.0 & 26.2 & 55.6 & 45.7 & 9.9 \\
\hline N1 & 44.3 & 33.1 & 61.0 & 41.2 & 19.8 \\
\hline N2 & 56.8 & 26.7 & 58.0 & 43.3 & 14.7 \\
\hline N3 & 58.0 & 34.5 & 54.9 & 42.3 & 12.6 \\
\hline N4 & 41.2 & 34.8 & 64.6 & 43.1 & 21.5 \\
\hline N5 & 55.1 & 37.4 & 57.8 & 40.9 & 17.0 \\
\hline N6 & 41.0 & 21.3 & 68.3 & 47.4 & 20.9 \\
\hline N7 & 52.5 & 42.0 & 55.7 & 38.6 & 17.1 \\
\hline N8 & 55.1 & 40.8 & 55.5 & 40.8 & 14.7 \\
\hline N9 & 50.2 & 35.9 & 58.8 & 41.6 & 17.2 \\
\hline
\end{tabular}

Fig. 5 demonstrates the evolution of the water contact angle for the PBII-treated PET samples. $\Theta_{w}$ for the treated samples depends mainly on the fluence, from among the treatment parameters. In particular, after treatments at low fluence $\left(1 \times 10^{17} \mathrm{~cm}^{-2}\right)$, the water contact angle may drop by $20^{\circ}$, while upon increasing fluence the extent of reduction of $\Theta_{w}$ becomes smaller $\left(3-17^{\circ}\right)$. A possible explanation can be the dynamic annealing [24], followed by a decreased post-treatment type surface oxidation.

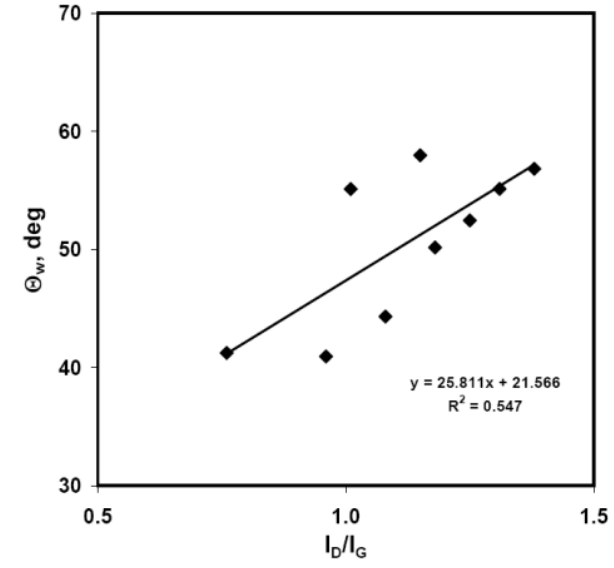

Fig. 5 Water contact angle versus area ratio of the D and G Raman bands

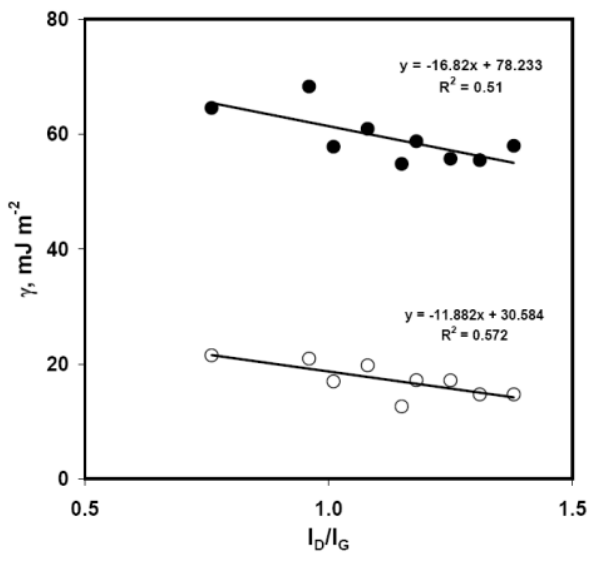

Fig. 6 Total surface energy $(\bullet)$ and its dispersive component $(O)$ versus area ratio of the $\mathrm{D}$ and $\mathrm{G}$ Raman bands

Fig. 5 shows a direct relationship between $\Theta_{w}$ and the $I_{D} / I_{G}$ ratio, while Fig. 6 demonstrates inverse relationships between $\gamma_{\text {tot }}$ and $I_{D} / I_{G}$ and between $\gamma_{\text {disp }}$ and $I_{D} / I_{G}$. The trends are obvious, although the points have a scatter, probably due to the variation in roughness. These figures reflect structure-property relationships for the He PBII-treated PET samples: the water contact angle increases and thus the surface wettability decreases, and simultaneously the total surface energy and its dispersive component decrease with the formation of surface structure, 
characterised by enhanced portion of $\mathrm{sp}^{2}$ carbon rings. These relationships are in agreement with our previous observation, according to which severe conditions of He PBII treatment of PET (increased voltage, fluence and fluence rate) lead to increased carbonisation (decreased O-content) and simultaneously to enhanced $I_{D} / I_{G}$ ratio [2]. These relationships are in agreement also with other published results, according to which $\gamma_{\text {disp }}$ decreases with the formation of nanocrystalline graphite upon annealing of amorphous hydrogenated carbon films [25].

\subsection{Changes in surface electrical resistance}

The surface electrical resistance $R$ for the untreated PET was higher than the upper limit of the measurement range of the equipment applied, which implies a starting value $R_{0}>10^{17} \Omega$. The values of $R$ determined for the PBII-treated PET samples, are collected in Table 4. As seen in this table, $R$ decreased substantially upon treatment reaching values ranging between $1.0 \times 10^{9}$ and $1.8 \times 10^{12} \Omega$. This implies a decrease by about 5 to 8 orders of magnitude. The strong decrease of electrical resistivity of PET and other polymers has already been reported upon PBII treatment in plasma gases like $\mathrm{Ar}, \mathrm{Xe}, \mathrm{O}_{2}$ and $\mathrm{N}_{2}$ [26-28], thus the results obtained in this work by He PBIII are in agreement with those of the previous publications.

Table 4

\section{Changes in the surface electrical resistance}

\begin{tabular}{cc}
\hline Sample & $\begin{array}{c}\boldsymbol{R} \\
\boldsymbol{\Omega} \times \mathbf{1 0}^{\mathbf{1 1}}\end{array}$ \\
\hline Untreated & $>10^{6}$ \\
\hline $\mathrm{N} 1$ & 6.4 \\
\hline $\mathrm{N} 2$ & 0.15 \\
\hline $\mathrm{N} 3$ & 0.2 \\
\hline $\mathrm{N} 4$ & 18.0 \\
\hline $\mathrm{N} 5$ & 1.0 \\
\hline $\mathrm{N} 6$ & 0.01 \\
\hline $\mathrm{N} 7$ & 6.0 \\
\hline $\mathrm{N} 8$ & 4.0 \\
\hline $\mathrm{N} 9$ & 8.3 \\
\hline
\end{tabular}




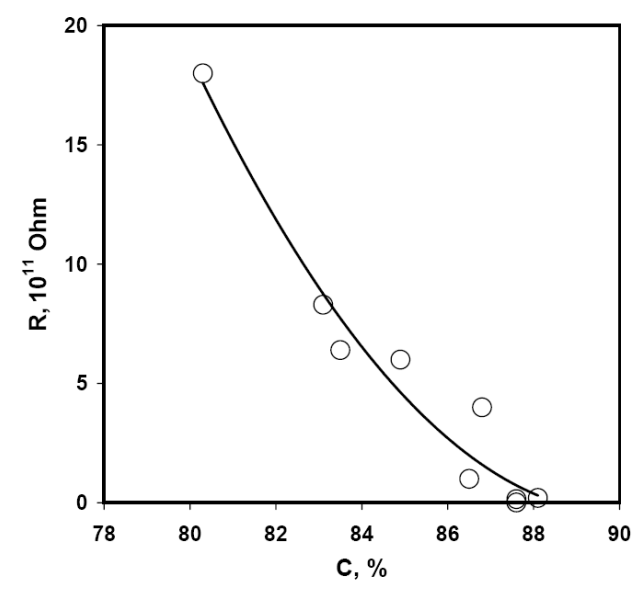

Fig 7 Surface electrical resistance of the He PBII-treated PET samples versus surface Ccontent

Fig. 7 demonstrates the evolution of $R$ vs. the surface C-content determined by XPS for the He PBII-treated PET samples. It can be seen that $R$ decreases significantly with the increase of the surface C-content of the PBII-treated samples, representing an apparently new composition-property type relationship. This relationship can be explained by the surface carbonisation effect detected by XPS and the increase of portion of aromatic $\mathrm{sp}^{2}$ carbon rings revealed by Raman spectroscopy. XPS studies of the C 1s peaks, additional to those performed previously on the changes in composition and bonding [2], complete and support this explanation. In particular, an examination of the weak $\pi \rightarrow \pi^{*}$ shake-up satellite at $291.6 \mathrm{eV}$ reveals an increase of this feature upon each He PBII treatment, proving the formation of extended conjugated $\pi$-electron system. Furthermore, the intensity ratio of the satellite to the main $\mathrm{C}$ 1s peak is inversely related to the surface electrical resistance, which is in agreement with the diagnostic role of the $\pi \rightarrow \pi^{*}$ shake-up satellite in the formation of conjugated double bond-rich conducting structures.

\section{Conclusion}

The following structure-property and composition-property relationships were obtained for the PET surfaces modified by He PBII treatments:

- Inverse correlations between lightness and $I_{D} / I_{G}$ ratio and between chroma and $I_{D} / I_{G}$ ratio, suggesting that the PBII-treated PET samples darken and their colourfulness decreases with the increase of the portion of aromatic $\mathrm{sp}^{2}$ carbon rings in the chemical structure of the modified layer. Owing to these correlations, colorimetry can be a simple method to yield chemical structure-related information.

- Direct correlation between water contact angle and the $I_{D} / I_{G}$ ratio and inverse correlations between surface energy and $I_{D} / I_{G}$ ratio and between dispersive component of surface energy and $I_{D} / I_{G}$ ratio, reflecting that surface wettability, surface energy and its dispersive component decrease with the formation of surface structure, characterised by enhanced portion of aromatic $\mathrm{sp}^{2}$ carbon rings.

- The surface electrical resistance decreased with the increase of the surface C-content determined by XPS and also with the increase of the surface concentration of conjugated double bonds, reflected by the increase of the $\pi \rightarrow \pi^{*}$ shake-up satellite of the $\mathrm{C} 1 \mathrm{~s}$ peak. 


\section{Acknowledgement}

This work was co-sponsored by the National Scientific Research Fund (OTKA) and the National Development Agency (NFÜ) through project K-67741.

\section{References}

[1] A. Tóth, K. Kereszturi, M. Mohai, I. Bertóti, Surf. Coat. Technol. 204 (2010) 28982908.

[2] A. Tóth, M. Veres, K. Kereszturi, M. Mohai, I. Bertóti, J. Szépvölgyi, Nucl. Instrum. Methods B 269 (2011) 1855-1858.

[3] M. Veres, M. Füle, S. Tóth, I. Pócsik, M. Koós, A. Tóth, M. Mohai, I. Bertóti, Thin Solid Films 482 (2005) 211-215.

[4] Y. Kim, Y. Lee, S. Han, K.-J. Kim, Surf. Coat. Technol. 200 (2006) 4763-4769.

[5] N. Mireault, G.G. Ross, Appl. Surf. Sci. 254 (2008) 6908-6914.

[6] K. Kereszturi, A. Tóth, M. Mohai, I. Bertóti, J. Szépvölgyi, Appl. Surf. Sci. 256 (2010) 6385-6389.

[7] J.X. Liao, W.M. Liu, T. Xu, C.R. Yang, H.W. Chen, C.L. Fu, W.J. Leng, Surf. Coat. Technol. 191 (2005) 90-95.

[8] J. Choi, K. Ishii, T. Kato, M. Kawaguchi, W. Lee, Diamond Relat. Mater. 20 (2011) 845-848.

[9] X. Ma, J. Li, M. Sun, Appl. Surf. Sci. 254 (2008) 6837-6841.

[10] J. Li, X. Ma, M. Sun, Zh. Song, Nucl. Instrum. Methods B 267 (2009) 482-486.

[11] A. Siddiqui, S. Nazzal, Int. J. Pharmaceut. 341 (2007) 173-180.

[12] D.K. Owens, R.C. Wendt, J. Appl. Polym. Sci. 13 (1969) 1741-1747.

[13] A.C. Ferrari, J. Robertson, Phys. Rev. B 61 (2000) 014095.

[14] A.C. Ferrari, J. Robertson, Phys. Rev. B 64 (2001) 075414.

[15] A.C. Ferrari, J. Robertson, Phil. Trans. R. Soc. Lond. A 362 (2004) 2477-2512.

[16] G.J.M. Fechine, M.S. Rabello, R.M. Souto Maior, L.H. Catalani, Polymer 45 (2004) 2303-2308.

[17] G.J.M. Fechine, M.S. Rabello, R.M. Souto Maior, Polym. Degrad. Stab. 75 (2002) 153-159.

[18] M. Laroussi, Plasma Process. Polym. 2 (2005) 391-400.

[19] D.M. Wiles, Pure \& Appl. Chem. 50 (1978) 291-297.

[20] Z. Zhu, Y. Sun, C. Liu, J. Liu, Y. Jin, Nucl. Instrum. Methods B 193 (2002) 271-277.

[21] C.F.L. Ciolacu, N.R. Choudhury, N.K. Dutta, Polym. Degrad. Stab. 91 (2006) 875885 .

[22] E.H. Lee, Nucl. Instrum. Methods B 151 (1999) 29-41.

[23] F. Piazza, G. Morell, Diam. Relat. Mater. 18 (2009) 43-50., and references therein.

[24] N.N. Andrianova, A.M. Borisov, E.S. Mashkova, Y.S. Virgiliev, Nucl. Instrum. Methods B 193 (2002) 271-277.

[25] P. Yang, J.Y. Chen, Y.X. Leng, H. Sun, N. Huang, P.K. Chu, Surf. Coat. Technol. 186 (2004) 125-130.

[26] Y. Lee, S. Han, H. Lim, Y. Kim, H. Kim, Anal. Bioanal. Chem. 373 (2002) 595-600.

[27] H. Lim, Y. Lee, S. Han, Y. Kim, J. Cho, K.-J. Kim, Surf. Coat. Technol. 160 (2002) 158-164.

[28] Z.J. Han, B.K. Tay, P.C.T. Ha, M. Shakerzadeh, A.A. Cimmino, S. Prawer, D. McKenzie, Appl. Phys. Lett. 91 (2007) art.no. 052103. 